\title{
The association between hydroxyurea adherence and opioid utilization among Texas Medicaid enrollees with sickle cell disease
}

Hyeun Ah Kang, PhD, and Jamie C Barner, PhD

\section{What is already known about this subject}

- Patients with sickle cell disease (SCD) suffer from recurrent catastrophic pain crises, and practice guidelines recommend opioid analgesics for pain management.

- Patients with SCD have been perceived as drug seekers or addicts by health care providers, and the current opioid epidemic further increased barriers for patients to obtain adequate opioids for pain management.

- Hydroxyurea was the only FDAapproved medication for SCD treatment until 2017, when other medications become available, and it has demonstrated beneficial effects in reducing pain crises; however, adherence to hydroxyurea among patients with SCD is suboptimal.

\section{ABSTRACT}

BACKGROUND: Individuals with sickle cell disease (SCD) suffer from recurrent catastrophic pain crises that are often managed by opioid analgesics. Being adherent to hydroxyurea has been associated with decreased health care resource use for pain; however, evidence of its association with opioid use is limited.

OBJECTIVE: To determine if adherence to hydroxyurea is associated with opioid use among patients with SCD.

METHODS: This retrospective study used Texas Medicaid data from September 1, 2011

\author{
What this study adds \\ - Texas Medicaid claims data were used \\ to show adherence of patients with SCD \\ to hydroxyurea and its association with \\ opioid use. \\ - Patients with SCD are moderately \\ adherent to hydroxyurea (medication \\ possession ratio $[M P R]=48.3 \%$ ). \\ - Being adherent to hydroxyurea \\ (MRP $\geq 80 \%$ ) was associated with a \\ lower risk of receiving a prescription for \\ strong opioids.
}

\author{
Author affiliations \\ Hyeun Ah Kang, PhD, The University of Texas \\ at El Paso School of Pharmacy, and Jamie C \\ Barner, PhD, The University of Texas at \\ Austin College of Pharmacy.
}

AUTHOR CORRESPONDENCE:

Hyeun Ah Kang, 915.747.8189,

hkang1@utep.edu
J Manag Care Spec Pharm. 2020;26(11):1412-22

Copyright $\odot 2020$, Academy of Managed Care Pharmacy. All rights reserved.

to August 31, 2016 (study period). The index date was the date of hydroxyurea initiation. Patients who were aged 2-63 years at the index date, had $\geq 1$ inpatient or $\geq 2$ outpatient SCD diagnoses during the study period, had $\geq 1$ hydroxyurea prescription during the identification period (September 1, 2011-August $31,2015)$, had no diagnosis of other indications for hydroxyurea during the study period, and were continuously enrolled for at least 12 months after the index date were included. Hydroxyurea adherence was measured using medication possession ratio (MPR). The study outcomes (measured 1-year post-index) were (a) opioid use; (b) number of opioid prescriptions; (c) strong opioid use (morphine, hydromorphone, fentanyl, and methadone); (d) number of strong opioid prescriptions; (e) high-dose opioid use ( $\geq 50 \mathrm{mg}$ morphine milligram equivalent [MME]); and (f) days supply for opioid prescriptions. Covariates included demographic (age and gender) and clinical (vaso-occlusive crisis [VOC], avascular necrosis, iron overload, acute chest syndrome, and blood transfusion) characteristics. Descriptive, bivariate (chi-square and Wilcoxon-Mann-Whitney tests), multiple logistic regression, and negative binomial regression analyses were performed.

RESULTS: 1,146 patients (18.3 [12.3] years) met the inclusion criteria. Of these, $19.6 \%$ were adherent to hydroxyurea (defined as 
MPR $\geq 80 \%$ ) and mean (SD) MPR was $48.3 \%$ (29.7\%). In the 1 year following hydroxyurea initiation, 923 (80.5\%) patients had $\geq 1$ opioid prescription with 7.6 (9.4) opioid prescriptions per patient, while 259 (22.6\%) patients had $\geq 1$ strong opioid prescription with 1.5 (4.4) strong opioid prescriptions per patient. Average (SD) opioid dose was 41.7 (74.3) $\mathrm{mg} M M E$, and $27.1 \%$ had high daily MME doses ( $\geq 50 \mathrm{mg}$ MME). Average (SD) opioid days supply was 83.1 (112.2) days. After adjusting for covariates, compared with being nonadherent, being adherent to hydroxyurea was associated with a $50.5 \%$ decreased risk of having strong opioids $(\mathrm{OR}=0.495,95 \% \mathrm{Cl}=0.278-0.879, \mathrm{P}=0.0165)$. Additionally, SCD-related complications (VOC, avascular necrosis, and iron overload) and older age were significant factors associated with opioid use and higher MME. Post hoc analyses showed that being adherent to hydroxyurea was significantly associated with lower probabilities of experiencing SCD-related complications.

CONCLUSIONS: Results showed that patients with SCD are moderately adherent to hydroxyurea. Being adherent to hydroxyurea was found to be associated with a lower risk of receiving a prescription for strong opioids. Findings suggest that close monitoring and interventions to improve adherence may help mitigate strong opioid use among these patients.

Sickle cell disease (SCD) is the most common inherited blood disorder in the United States and affects approximately 100,000 people. ${ }^{1,2}$ Affected individuals who were born with a defect in the gene for hemoglobin suffer from recurrent catastrophic pain crises and complications that typically lead to costly emergency department (ED) visits and hospitalizations. ${ }^{3-7}$ It is estimated that the annual U.S. total medical expenditures for SCD is over $\$ 2.4$ billion. ${ }^{8}$

The hallmark of SCD is recurrent and unpredictable attacks of acute painful crises, called vaso-occlusive crisis (VOC), and it is the most common cause of hospitalization for this population. ${ }^{4}$ Since this pain seriously affects patients' daily lives and is experienced throughout their lifespans, pain control is closely related to quality of life, as well as medical service use..$^{9-12}$

To control the pain crises among patients with SCD, guidelines recommend opioid analgesic ${ }^{13-16}$-weak opioids for moderate pain and strong opioids for severe pain. ${ }^{16}$ Since the majority of painful episodes are managed at home ${ }^{16-19}$ it is common for these patients to have opioids prescribed for home use. However, qualitative studies have found that patients with SCD frequently cite dissatisfaction with the quality of pain management provided to them. ${ }^{20,21}$ Although studies have reported that the risks of developing dependence and addiction to opioids are very low among this population, ${ }^{22}$ patients with SCD have been misclassified as drug seekers by providers, especially those who are not familiar with this disease, because of their chronic need for narcotic medications during painful events..$^{23,24}$

Patients have reported that the enhanced restriction on prescribing opioids, such as the recent guideline published by the Centers for Disease Control and Prevention (CDC), following the current opioid epidemic, further increases the difficulty in using opioids. ${ }^{20}$ To address this issue, the American Society of Hematology and other organizations requested that the $\mathrm{CDC}$ clearly acknowledge that special consideration is required for the pain management of patients with SCD, as well as those with cancer, in order to ensure appropriate access to opioid therapy. ${ }^{25}$ Along with these efforts, treatment for these patients should aim to prevent the pain episodes, which could decrease the need for prescription opioids.

Before June 2017, hydroxyurea was the only medication approved by the U.S. Food and Drug Administration for SCD treatment. It has demonstrated beneficial effects in pain control such as decreased number of VOC events, shorter length of hospital stay, and lower dose of daily opioids used. ${ }^{17,26}$ However, according to the studies that used objective methods in relatively large populations ( $>50$ patients with SCD), adherence to hydroxyurea is suboptimal, ${ }^{27-30}$ which is related to the most common reason why physicians do not prescribe it. ${ }^{31-33}$ Hydroxyurea adherence has been associated with improvement in several outcomes, including number of VOC events, hospitalization, readmission, ED visits, and medical costs. ${ }^{29,34}$

A recent study (2010) examined the association between the number of hydroxyurea refills and opioid use and found that patients with 12 or more hydroxyurea refills had significantly fewer opioid prescriptions than those with fewer than 12 refills. ${ }^{35}$ However, despite the importance of prevention of pain and opioid use in this population, evidence of the association between hydroxyurea adherence and opioid use among patients with SCD is limited. Therefore, the purpose of this study was to investigate hydroxyurea adherence and its association with opioid use among patients with SCD.

\section{Methods}

\section{STUDY DESIGN AND DATA SOURCE}

This was a retrospective database study using Texas Medicaid claims data from September 2011 through August 2016. These data include deidentified patient unique numbers; demographic information (age and gender); medical information (date of service received, codes for diagnosis and procedures, and costs); and pharmacy information (dispense 
date, medication name and dose, quantity, number of days supplied, and costs). The study was approved by the University of Texas at Austin Institutional Review Board.

\section{STUDY POPULATION}

Texas Medicaid recipients who had evidence of hydroxyurea use between September 2011 and August 2015 (identification period) were selected. The index date was designated as the date of the first hydroxyurea claim within the identification period. Pharmacy claims for hydroxyurea were identified by relevant Generic Code Number Sequence Numbers in the pharmacy file.

Subjects were required to be aged between 2 and 63 years (to avoid Medicaid/Medicare dual eligibility) at the index date and to have at least 1 hospitalization or 2 outpatient visits associated with an SCD diagnosis during the identification period. International Classification of Diseases, Ninth/Tenth Revision, Clinical Modification (ICD9-CM) codes 282.41, 282.42, 282.60-282.69 and (ICD-10-CM) codes D57, D57.x (except for 57.3; sickle cell trait), and D57. $\mathrm{xx}$ were used to identify SCD diagnoses. Only subjects who were enrolled in Texas Medicaid for at least 12 months after the index date were included.

Finally, subjects were excluded if they were diagnosed with any other indication for hydroxyurea (i.e., melanoma, resistant chronic myeloid leukemia, locally advanced squamous cell carcinomas of the head and neck, and recurrent, metastatic, or inoperable carcinoma of the ovary) during the study period.

\section{STUDY VARIABLES}

Baseline characteristics such as age and gender were assessed at the index date, and SCD-related complications that were potentially or shown to be associated with highdose opioid use were measured during the 1-year post-index period. ${ }^{36}$ The complications include VOC (ICD-9-CM codes 282.42, 282.62, 282.64, and 282.69 or ICD-10-CM codes D57.0, D57.00, D57.21, D57.29, D57.41, D57.419, D57.81, and D57.819); avascular necrosis (ICD-9-CM codes 733.40-44 and 733.49 or ICD-10-CM codes M87.3, M87.3x, M87.3xx, M87.8, M87.8x, M87.8xx, and M87.9); iron overload (ICD9-CM code 275.02 or ICD-10-CM code E83.111); and acute chest syndrome (ICD-9-CM code 517.3 or ICD-10-CM codes D57.01, D57.211, D57.411, and D57.811). Information on the use of blood transfusion (Current Procedural Terminology codes 36430-36460 or ICD-9-CM codes 99.0, 99.01, 99.02, and V58.2) was also collected during the post-index period.

Medication adherence to hydroxyurea was measured using the medication possession ratio (MPR), defined as sum of the days supply of hydroxyurea claims dispensed during the 12 months after the index date divided by the number of days in the follow-up period (365). Based on the MPR obtained, individuals whose MPR was $80 \%$ or greater were categorized as adherent, while those with less than $80 \%$ were nonadherent. This cut-off value was chosen because it was used in most medication adherence studies. ${ }^{37}$

The study outcome was opioid use during the 1-year post-index period, which was classified as (a) evidence of opioid use; (b) number of opioid prescriptions; (c) evidence of strong opioid use (morphine, hydromorphone, fentanyl, and methadone) $)^{36,38}$; (d) number of strong opioid prescriptions; (e) evidence of high-dose opioid use, defined as $\geq 50 \mathrm{mg}$ morphine milligram equivalent (MME) according to the CDC guideline ${ }^{39}$; and (f) sum of days supply for opioid prescriptions. MME was calculated as daily dose multiplied by a drug-specific morphine conversion factor as follows: hydromorphone $=4$, fentanyl transdermal patch $(\mathrm{mcg} / \mathrm{hr})=2.4$, fentanyl buccal tablet $(\mathrm{mcg})=0.13$, methadone $=3$, codeine $=0.15$, hydrocodone $=1$, oxycodone $=1.5$, meperidine $=0.1$, and tramadol $=0.1 .^{39,40}$ Based on the MME computed, subjects were categorized into low-dose $(<50 \mathrm{mg}$ MME) versus high-dose ( $\geq 50 \mathrm{mg}$ MME) users.

\section{DATA ANALYSES}

Baseline characteristics and clinical conditions (complications and blood transfusion) of the study population were compared by hydroxyurea adherence status (adherent vs. nonadherent) using Wilcoxon-Mann-Whitney $U$ and chisquare tests. The main outcomes of interest were compared by hydroxyurea adherence status and age group (2-12, 13-18, 19-27, 28-45, and 46-63 years) using Kruskal-Wallis and chisquare tests. In addition, multivariate analyses were conducted to assess if dichotomized MPR was associated with the main outcomes, while controlling for the following covariates: age group; gender; history of medical conditions (VOC event, avascular necrosis, iron overload, and acute chest pain); and blood transfusion. Specifically, multivariate logistic regression analyses were performed for dichotomized dependent variables (i.e., opioid use, strong opioid use, and high-dose opioid use), while generalized linear models (GLM) were used for continuous variables. The Modified Park test revealed that the gamma distribution was appropriate to use for GLM for the number of strong opioids, while the negative binomial distribution was used for the number of opioids, daily MME, and opioid days supply. All data management and analyses were performed using SAS version 9.4 (SAS Institute, Cary, NC) and Stata 15 (StataCorp, College Station, TX). 


\section{FIGURE 1 Study Cohort Selection and Subject Exclusion}

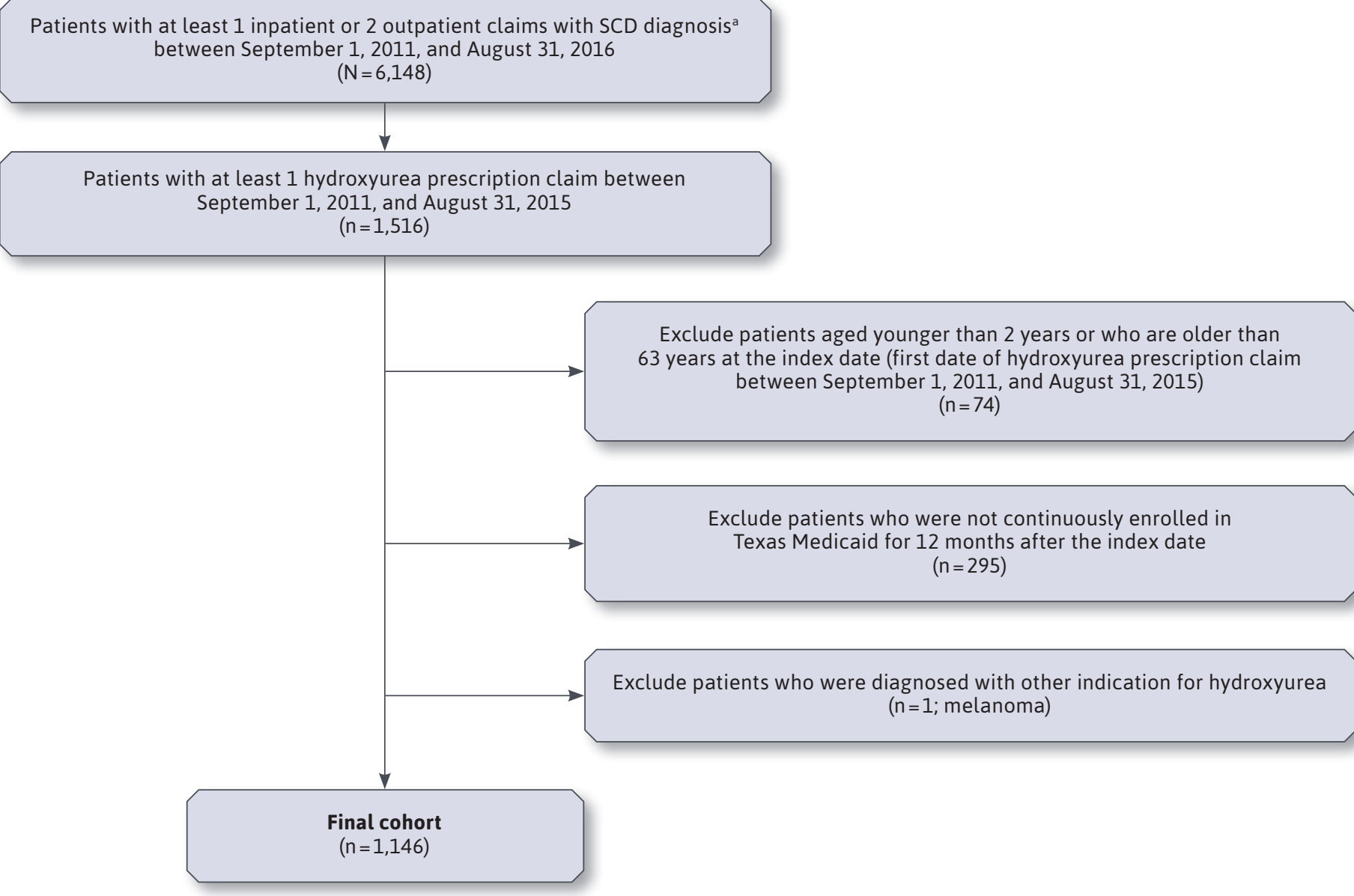

aCD-9-CM codes 282.41, 282.42, and 282.60-282.69 or ICD-10-CM codes D57, D57.x (except for 57.3; sickle cell trait), and D57.xx. ICD-9/10-CM = International Classification of Diseases, Ninth/Tenth Revision, Clinical Modification; $S C D=s i c k l e$ cell disease.

\section{Results}

\section{PATIENT AND CLINICAL CHARACTERISTICS AND MEDICATION ADHERENCE TO HYDROXYUREA}

After applying all study inclusion and exclusion criteria, 1,146 patients with SCD (aged 18.3 [12.3] years) were included in this study (Figure 1 and Table 1). As expected, a majority of patients were $\leq 18$ years $(57.2 \%)$, and adherent patients were significantly younger than nonadherent patients $(P<0.0001)$. Because of the small proportion, the age group 46-63 years was combined with the age group 28-45 years for subsequent analyses. Approximately half (50.2\%) were male. For the SCD-related clinical characteristics that were associated with opioid use,$^{36}$ almost three quarters (74.6\%) had at least 1 VOC during the 1-year follow-up period, and a significantly higher proportion of nonadherent patients experienced VOC than those who were adherent $(\mathrm{P}<0.0001)$. Similarly, avascular necrosis and iron overload were experienced by a higher proportion of nonadherent patients than those who were adherent $(P<0.0002$ and $P<0.0021$, respectively). Among adherent patients, only $3.6 \%$ had a blood transfusion, while almost $10 \%(9.2 \%)$ of nonadherent patients received a blood transfusion $(P=0.0052)$. Three complications (VOC, avascular necrosis, and acute chest syndrome) and blood transfusion were used as covariates in the multivariate analyses. Overall mean (SD) MPR was $48.3 \%$ (29.7\%), and 225 (19.6\%) patients were adherent to hydroxyurea (defined as MPR $\geq 80 \%$ ). 


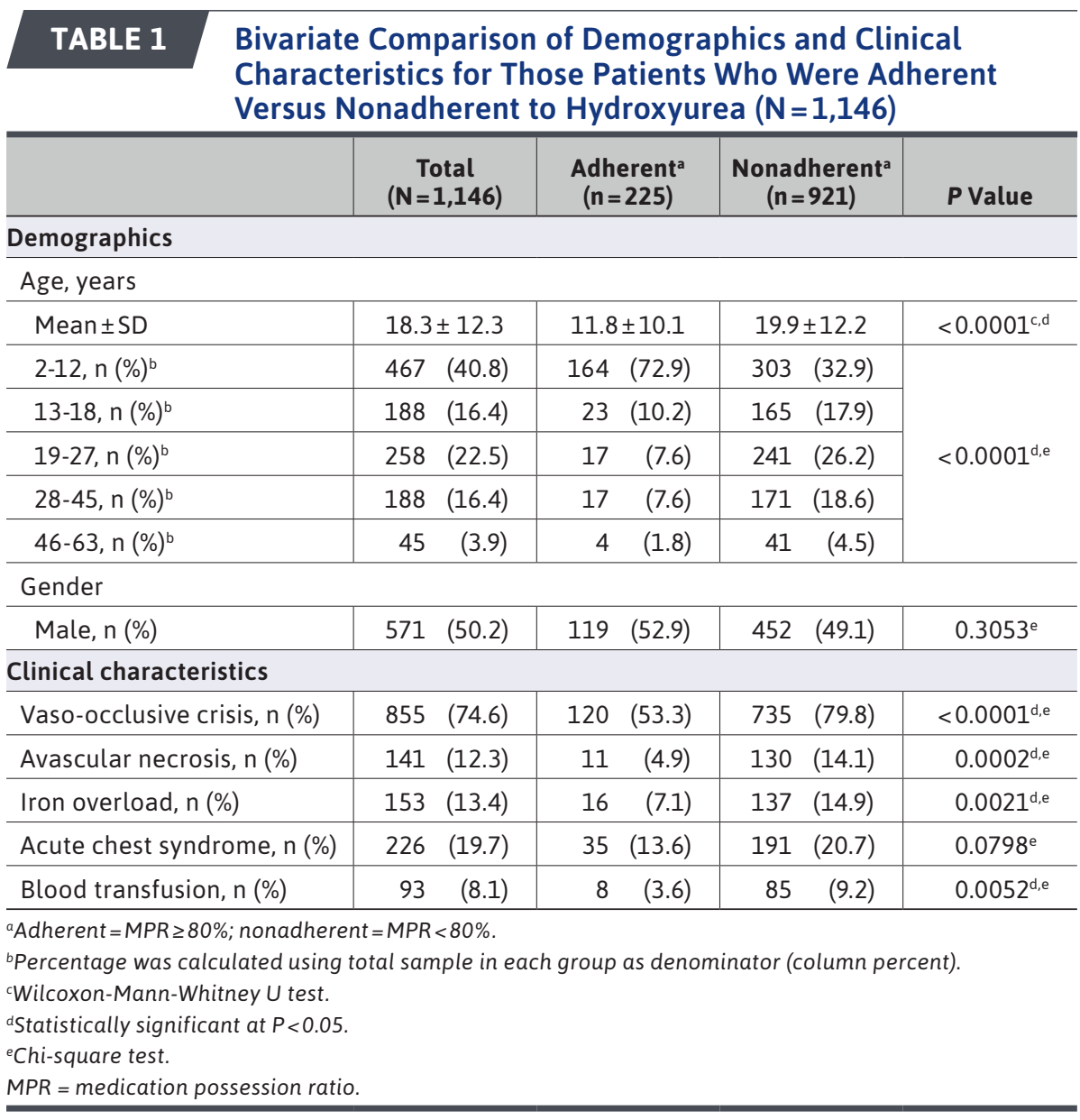

\section{STUDY OUTCOMES: UNADJUSTED RESULTS}

Table 2 shows unadjusted comparisons of opioid use by hydroxyurea adherence and age group. Overall, in the 1 year following hydroxyurea initiation, $923(80.5 \%)$ patients had at least 1 opioid prescription with 7.6 (9.4) opioid prescriptions per patient, while 259 (22.6\%) patients had at least 1 strong opioid prescription with 1.5 (4.4) strong opioid prescriptions per patient. Average (SD) daily dose of opioids was 41.7 (74.3) mg MME, and 311 (27.1\%) patients had a high daily MME dose ( $\geq 50 \mathrm{mg}$ MME). Average (SD) opioid days supply was almost 3 months (83.1 [112.2] days).
Bivariate analyses showed that adherent patients, compared with those nonadherent, had significantly lower probability of having opioids, strong opioids, and high-dose opioids (for every result $\mathrm{P}<0.0001$ ). Compared with nonadherent patients, adherent patients were also associated with significantly fewer number of prescriptions for both opioids and strong opioids, lower dose of opioids, and fewer days prescribed for opioids (for every result $\mathrm{P}<0.0001$ ). Bivariate analyses also showed that older age was associated with a higher probability of having opioids, strong opioids, and high-dose opioids and a greater number of prescriptions for opioids and strong opioids, a higher dose of opioids, and a greater number of days prescribed for opioids $(\mathrm{P}<0.0001)$. Figure 2 shows that daily MME and the number of prescriptions for opioids and strong opioids increased across age groups, whereas hydroxyurea adherence decreased until 27 years and then slightly increased.

\section{STUDY OUTCOMES: ADJUSTED RESULTS}

Table 3 includes the results of the adjusted comparisons of opioid use between adherent and nonadherent patients. Logistic regression showed that, compared with not being adherent, being adherent to hydroxyurea was associated with a 50.5\% decreased risk of having strong opioids $(\mathrm{OR}=0.495,95 \% \mathrm{CI}=0.278-0.879$, $\mathrm{P}=0.0165)$, after controlling for other demographic and clinical characteristics. However, none of the other relationships were significant. Regarding covariates, having SCD-related complications (VOC, avascular necrosis, and iron overload) and older age were significantly related to greater opioid use (see Supplementary Tables 1-7, available in online article).

\section{Discussion}

\section{HYDROXYUREA ADHERENCE}

Our population of 1,146 hydroxyurea users were moderately adherent $(48.3 \%$ mean MPR), and only $19.6 \%$ were adherent (MPR $\geq 80 \%)$ to their therapy. This finding is within a range of adherence in other Medicaid claims database studies. ${ }^{28-30}$ Young pediatric patients (aged 2-12 years) were significantly more adherent than older patients, which is also consistent with previous findings that revealed significant relationship with age-older age was associated with poorer adherence. ${ }^{41-45}$ 


\section{TABLE 2} Opioid Us
$(\mathrm{N}=1,146)$

\begin{tabular}{|c|c|c|c|c|c|c|c|c|c|}
\hline & \multirow[b]{2}{*}{$\begin{array}{c}\text { Total } \\
\mathrm{N}=1,146\end{array}$} & \multicolumn{3}{|c|}{ Adherence } & \multicolumn{5}{|c|}{ Age (Years) } \\
\hline & & $\begin{array}{c}\mathrm{MPR} \geq 80 \% \\
(\mathrm{n}=225)\end{array}$ & $\begin{array}{c}\mathrm{MPR}<80 \% \\
(\mathrm{n}=921)\end{array}$ & $P$ Value & $\begin{array}{c}2-12 \\
(n=467)\end{array}$ & $\begin{array}{c}13-18 \\
(n=188)\end{array}$ & $\begin{array}{c}19-27 \\
(n=258)\end{array}$ & $\begin{array}{c}28-63 \\
(n=233)\end{array}$ & P Value \\
\hline Opioid use, n (\%) & $\begin{array}{c}923 \\
(80.5)\end{array}$ & $\begin{array}{l}149 \\
(66.2)\end{array}$ & $\begin{array}{c}774 \\
(84.0)\end{array}$ & $<0.0001^{b, c}$ & $\begin{array}{c}304 \\
(65.1)\end{array}$ & $\begin{array}{l}157 \\
(83.5)\end{array}$ & $\begin{array}{c}240 \\
(93.0)\end{array}$ & $\begin{array}{c}222 \\
(95.3)\end{array}$ & $<0.0001^{b, c}$ \\
\hline $\begin{array}{l}\text { Number of opioid prescriptions, } \\
\text { mean } \pm \text { SD, (median) }\end{array}$ & $\begin{array}{l}7.6 \pm 9.4 \\
(4)\end{array}$ & $\begin{array}{l}3.7 \pm 6.1 \\
(1)\end{array}$ & $\begin{array}{l}8.6 \pm 9.8 \\
(5)\end{array}$ & $<0.0001^{b, d}$ & $\begin{array}{l}2.5 \pm 4.3 \\
(1)\end{array}$ & $\begin{array}{c}6.1 \pm 6.7 \\
(4)\end{array}$ & $\begin{array}{l}12.0 \pm 10.9 \\
(9)\end{array}$ & $\begin{array}{l}14.3 \pm 10.7 \\
(12)\end{array}$ & $<0.0001^{\text {bee }}$ \\
\hline Strong opioid use, $\mathrm{n}(\%)^{\mathrm{a}}$ & $\begin{array}{l}259 \\
(22.6)\end{array}$ & $\begin{array}{l}16 \\
(7.1)\end{array}$ & $\begin{array}{c}243 \\
(26.4)\end{array}$ & $<0.0001^{b, c}$ & $\begin{array}{c}38 \\
(8.1)\end{array}$ & $\begin{array}{c}45 \\
(23.9)\end{array}$ & $\begin{array}{c}87 \\
(33.7)\end{array}$ & $\begin{array}{c}89 \\
(38.2)\end{array}$ & $<0.0001^{b, c}$ \\
\hline $\begin{array}{l}\text { Number of strong opioid pre- } \\
\text { scriptions, mean } \pm \text { SD (median) }\end{array}$ & $\begin{array}{c}1.5 \pm 4.4 \\
(0)\end{array}$ & $\begin{array}{l}0.4 \pm 2.2 \\
(0)\end{array}$ & $\begin{array}{l}1.7 \pm 4.7 \\
(0)\end{array}$ & $<0.0001^{b, d}$ & $\begin{array}{l}0.3 \pm 1.7 \\
(0)\end{array}$ & $\begin{array}{c}1.2 \pm 3.9 \\
(0)\end{array}$ & $\begin{array}{l}2.1 \pm 4.8 \\
(0)\end{array}$ & $\begin{array}{l}3.3 \pm 6.6 \\
(0)\end{array}$ & $<0.0001^{\text {b,e }}$ \\
\hline $\begin{array}{l}\text { MME daily, mean } \pm \text { SD } \\
\text { (median) }\end{array}$ & $\begin{array}{l}41.7 \pm 74.3 \\
(30.0)\end{array}$ & $\begin{array}{l}24.4 \pm 63.6 \\
(12.6)\end{array}$ & $\begin{array}{c}46.0 \pm 76.1 \\
(33.8)\end{array}$ & $<0.0001^{b, d}$ & $\begin{array}{c}15.1 \pm 19.7 \\
(10.8)\end{array}$ & $\begin{array}{c}43.8 \pm 37.8 \\
(38.1)\end{array}$ & $\begin{array}{l}60.7 \pm 61.9 \\
\quad(47.3)\end{array}$ & $\begin{array}{l}72.5 \pm 135.1 \\
(47.7)\end{array}$ & $<0.0001^{\text {bee }}$ \\
\hline $\begin{array}{l}\text { High MME daily use } \\
(\geq 50 \mathrm{MME}), \mathrm{n}(\%)^{\mathrm{a}}\end{array}$ & $\begin{array}{c}311 \\
(27.1) \\
\end{array}$ & $\begin{array}{c}26 \\
(11.6) \\
\end{array}$ & $\begin{array}{c}285 \\
(30.9) \\
\end{array}$ & $<0.0001^{b, c}$ & $\begin{array}{c}22 \\
(4.7) \\
\end{array}$ & $\begin{array}{c}66 \\
(35.1) \\
\end{array}$ & $\begin{array}{c}114 \\
(44.2) \\
\end{array}$ & $\begin{array}{c}109 \\
(46.8) \\
\end{array}$ & $<0.0001^{b, c}$ \\
\hline $\begin{array}{l}\text { Opioid days supply, } \\
\text { mean } \pm \text { SD (median) }\end{array}$ & $\begin{array}{c}83.1 \pm 112.2 \\
(25)\end{array}$ & $\begin{array}{c}38.6 \pm 81.0 \\
(8)\end{array}$ & $\begin{array}{c}94.0 \pm 116.0 \\
(35)\end{array}$ & $<0.0001^{b, d}$ & $\begin{array}{c}17.0 \pm 35.5 \\
(7)\end{array}$ & $\begin{array}{c}40.9 \pm 57.6 \\
(21)\end{array}$ & $\begin{array}{c}136.7 \pm 119.9 \\
(97)\end{array}$ & $\begin{array}{c}190.3 \pm 126.4 \\
(186)\end{array}$ & $<0.0001^{\text {bee }}$ \\
\hline
\end{tabular}

aPercentage was calculated using total sample in each group as denominator (column percent).

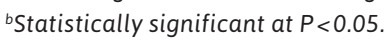

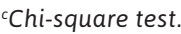

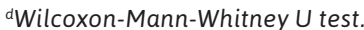

eKruskal-Willis test.

$M M E=$ morphine miligram equivalent; $M P R=$ medication possession ratio.

\section{OPIOID USE}

More than $80 \%$ of patients used opioids, and more than $20 \%$ used strong opioids during the 1-year follow-up period, which is higher than previous studies that have examined opioid use among patients with SCD. ${ }^{28,36,46,47}$ Prevalence may have been higher in our population because it was restricted to hydroxyurea users. These patients typically have more SCD severity given that hydroxyurea is recommended for patients who have 3 or more SCD-related moderate to severe pain crises in a 12 -month period. ${ }^{13}$ In addition, previous studies revealed that hydroxyurea users are more likely to be prescribed opioids, and they are associated with highdose opioid use. ${ }^{36,46}$ Ballas et al. (2018) found that a higher proportion of Medicaid patients with SCD used opioids compared with commercially insured patients with SCD. ${ }^{47}$

Mean (SD) number of opioids used per year (7.6 [9.4]) was similar to findings from Medicaid enrollees with SCD across the United States and greater than overall Medicaid enrollees in Georgia. ${ }^{47,48}$ Average (SD) daily dose of opioids was 41.7 (74.3) $\mathrm{mg}$ (median=30 mg) MME, and 331 (27.1\%) patients had high daily MME doses $\geq 50 \mathrm{mg}$ MME. This is within the range of previously reported daily opioid doses among patients with SCD regardless of hydroxyurea use, most or all of which were enrolled in Medicaid, ${ }^{36,47}$ and lower than that from patients with chronic noncancer pain consuming a median dose of $75 \mathrm{mg}$ MME per day. ${ }^{49}$

The average (SD) number of days prescribed for opioids (opioid days supply) was almost 3 months (83.1 [112.2] days). This is within the range of that for general Medicaid enrollees excluding cancer patients. ${ }^{48}$ However, it is shorter than the average among the Medicaid patients with SCD across the United States (106.1-122.5 days). ${ }^{47}$

Among demographic characteristics, older age was associated with higher opioid use that included probability of having opioids, strong opioids, and high-dose opioids; greater number of prescriptions for opioids and strong opioids; higher dose of opioids; and greater number of days prescribed for opioids. This is consistent with previous findings showing that older patients used more opioids among patients with SCD. ${ }^{36,46,47}$ This finding is not surprising given that pain develops over the lifetime of individuals with the disease in terms of its frequency and severity. ${ }^{50}$ 


\section{FIGURE 2 Opioid Use and Hydroxyurea Adherence by Age Group $(\mathrm{N}=1,146)$}

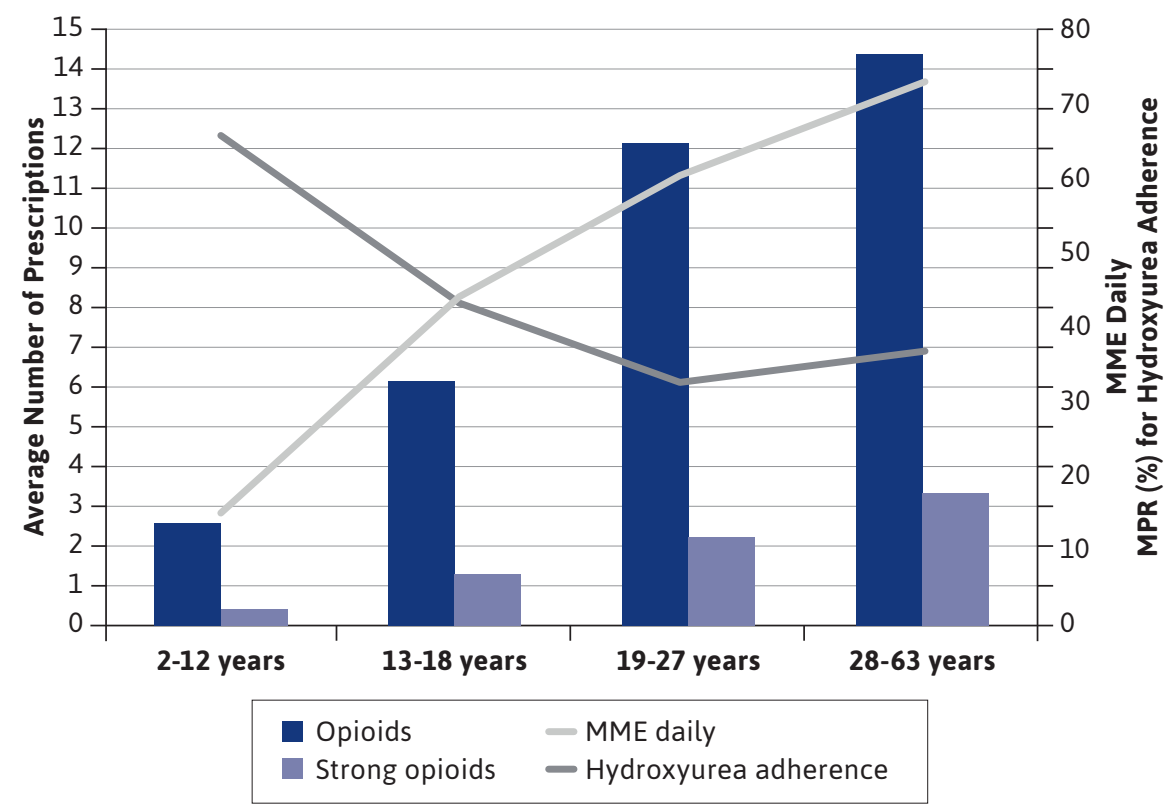

$\mathrm{MME}=$ morphine milligram equivalent; $\mathrm{MPR}=$ medication possession ratio hydroxyurea adherence in mitigating complications that require increased opioid use. Post hoc analyses showed that being adherent to hydroxyurea was significantly associated with lower probabilities of experiencing VOC $(\mathrm{OR}=0.432,95 \% \mathrm{CI}=0.310-0.602$, $\mathrm{P}<0.0001)$, while controlling the covariates used in this study.

\section{IMPLICATIONS}

Managing opioid use in this population is important in reducing adverse events associated with long-term use of opioids, including dependence and respiratory depression. However, opioid use among this population is needed to address the complex and painful VOC crises. Practice guidelines for SCD indicate oral, parenteral, and even strong opioids for the management of SCD pain episodes, ${ }^{13-16}$ and Elander et al. (2003) revealed that most opioid use among this population were associated with pain relief, with very few associated with substance abuse. $^{22}$ In addition, opioid-related death rates in SCD are substantially lower than in other diseases..$^{51}$ Unfortunately, patients with SCD have been misclassified as drug-seekers by providers who are not familiar with this disease and the characteristics of the pain symptoms these patients experience. ${ }^{23,24}$ Because recent guidelines restricting opioid use could negatively affect opioid access among this population, the CDC and the Centers for Medicare \& Medicaid Services recently acknowledged that pain management for patients with SCD, as well as those with cancer, require special consideration to ensure that patients have access to clinically appropriate opioid therapy. ${ }^{25,52}$

Along with these efforts, the strategy for managing opioid use among this population should focus more on reducing pain episodes and complications, rather than on restricting opioid use. Results from this study suggest 


\section{TABLE 3}

Multivariate Analyses Examining the Association Between Hydroxyurea Adherence and Opioid Use $(\mathrm{N}=1,146)$

\begin{tabular}{|c|c|c|c|c|}
\hline \multirow{2}{*}{$\begin{array}{l}\text { Primary Independent Variable: Hydroxyurea } \\
\text { Adherence (reference: MPR }<80 \% \text { ) }\end{array}$} & \multirow[b]{2}{*}{ Estimate } & \multicolumn{2}{|c|}{ Confidence Interval } & \multirow[b]{2}{*}{ P Value } \\
\hline & & Lower & Upper & \\
\hline \multicolumn{5}{|l|}{ Odds ratio } \\
\hline Opioids & 0.829 & 0.568 & 1.209 & $0.3305^{\mathrm{a}}$ \\
\hline Strong opioids & 0.495 & 0.278 & 0.879 & $0.0165^{a, b}$ \\
\hline Higher MME daily ( $\geq 50$ mg MME) & 0.861 & 0.518 & 1.430 & $0.5628^{\mathrm{a}}$ \\
\hline \multicolumn{5}{|l|}{ Incidence rate ratio } \\
\hline Number of opioids & 0.871 & 0.736 & 1.032 & $0.110^{c}$ \\
\hline MME daily & 0.919 & 0.764 & 1.107 & $0.374^{c}$ \\
\hline Opioid days supply & 0.954 & 0.767 & 1.187 & $0.674^{c}$ \\
\hline \multicolumn{5}{|l|}{ Relative risk } \\
\hline Number of strong opioids & 0.919 & 0.573 & 1.473 & $0.726^{d}$ \\
\hline \multicolumn{5}{|c|}{$\begin{array}{l}\text { Note: Covariates: age group (2-12,13-18, 19-27, 28-63), gender, evidence of sickle-cell related complications } \\
\text { (vaso-occlusive crisis, avascular necrosis, and iron overload), and evidence of blood transfusion. } \\
\text { aMultiple logistic regression. } \\
\text { 'Statistically significant at } P<0.05 \text {. } \\
{ }^{c} \text { Negative binomial regression. } \\
{ }^{\mathrm{d} G e n e r a l i z e d ~ l i n e a r ~ m o d e l ~ w i t h ~ g a m m a ~ d i s t r i b u t i o n ~ w i t h ~ l o g ~ l i n k . ~} \\
\text { MME = morphine milligram equivalent; MPR=medication possession ratio. }\end{array}$} \\
\hline
\end{tabular}

that being adherent to hydroxyurea could be beneficial in mitigating strong opioid use.

Several barriers to hydroxyurea adherence have been documented: fear of side effects, forgetting, and complex medication regimen. ${ }^{53}$ And it has been shown that multicomponent interventions, especially combining behavioral components (monitoring, goal setting, providing rewards, and linking medication taking with established routines) are more effective than just educational interventions for pediatric patients with chronic illness. ${ }^{54,55}$

This study also confirmed that the trend of transition from pediatrics into adult care (aged 13-27 years) was associated with a remarkable decrease in hydroxyurea adherence and an increase in opioid use. Providers and caregivers may consider closer monitoring of patients as they approach adolescence, since this seems to be an inflection point signaling decreased hydroxyurea adherence. In addition to providing targeted programs to promote medication adherence among patients with SCD, psychosocial and behavioral treatment such as relaxation training, operant behavioral strategies, biofeedback, and cognitive coping would also benefit patients to reduce pain episodes and opioid use. . $^{39,56,57}$

\section{LIMITATIONS}

This is the first study that has investigated the association between hydroxyurea adherence and opioid use among patients with SCD. Despite this strength, however, study findings should be interpreted with caution because of limitations inherent in the patient population and study design.

First, our population may not be representative of the national SCD population, especially with other forms of insurance or with the uninsured. However, Texas has a relatively large African-American population, and it is estimated that two thirds of patients with SCD are publicly insured, ${ }^{58,59}$ which could make our study findings more generalizeable.

Second, this study included patients who had 1 or more hydroxyurea prescriptions within the study period. Since SCD is an inherited and chronic condition, and hydroxyurea is a preventive therapy, a fixed interval (365 days) was used for the MPR calculation, which did not require limiting the patients to those who had 2 or more prescriptions. However, inclusion of patients having only 1 prescription may have resulted in the inclusion of those who had to stop the therapy because of adverse effects.

Third, opioids that were administered in an inpatient acute care setting (ED or inpatient) were not captured due to limitations of the data. Thus, our study primarily focused on opioid use at home. Ballas et al. (2010) found that about $96 \%$ of VOC-related acute care contacts were treated with parenteral opioids, ${ }^{17}$ so there is a need for future studies to understand overall opioid use in more intensive care environments.

Fourth, categorization of strong opioids was determined according to the recommendations made for pain management for patients with SCD in previous literature and pharmacotherapy guidance. ${ }^{36,38}$ However, this may not reflect current practice, where physicians may prescribe oxycodone for the treatment of severe pain among patients with SCD. In additional analyses, where oxycodone was classified as a strong opioid, the extent of the association between hydroxyurea adherence and the probability of having a strong opioid was no longer significant $(P=0.1555)$. However, the association remained significant among pediatric patients (aged $<19$ years; $\mathrm{n}=655 ; \mathrm{OR}=0.408$, 95\% CI $=0.203-0.821, P=0.0120$ ). 
Fifth, because medication adherence and opioid use were measured during the same period, the association between nonadherence and higher strong opioid use does not necessarily indicate a causal relationship. Therefore, prospective studies are needed to further understand this relationship.

Finally, this study has limitations inherent in studies that use administrative claims data. Medical conditions were identified based on ICD-9-CM and ICD-10-CM codes in the database, so the validity of the results, in part, depends on the accuracy of the coding. We also do not know if hydroxyurea was actually taken by patients as filled. Therefore, medication adherence could be lower than what was documented in the database. Although these limitations are from indirect measures of adherence and outcomes, Candrilli et al. (2011) also found that adherence using pharmacy refill data was associated with patient outcomes. ${ }^{29}$

\section{Conclusions}

Our results showed that patients with SCD are moderately adherent to hydroxyurea and being adherent to hydroxyurea was associated with a lower risk of having strong opioids. Older age and SCD-related complications such as VOC, avascular necrosis, and iron overload were also linked to greater opioid use. Because the probabilities of having these complications were negatively associated with hydroxyurea adherence, interventions to improve adherence to hydroxyurea may help decrease opioid use by reducing SCD complications, especially $\mathrm{VOC}$ that is directly associated with pain, in this population.

\section{DISCLOSURES}

This research did not receive any specific funding. Barner and Kang report grants from Novartis Pharmaceuticals, unrelated to this work.

A part of this study was presented as a poster at the American Pharmacists Association (APhA) 2019 Annual Meeting and Exposition (March 22-25, 2019, Seattle, WA) and received the 2019 APhA-APRS Presentation Award in the APhA-APRS Contributed Research Paper, Graduate Student/Fellow/Postdoctoral Scholar category.

\section{ACKNOWLEDGMENTS}

The authors thank the Texas Health and Human Services Commission for the provision of data and Kristin M. Richards, $\mathrm{PhD}$, for assistance with data acquisition and cleaning.

\section{REFERENCES}

1. Centers for Disease Control and Prevention. What is sickle cell disease? Last reviewed October 21, 2019. Accessed September 30, 2020. https://www.cdc. gov/ncbddd/sicklecell/facts.html

2. National Organization for Rare Disorders. Sickle cell disease. Accessed September 30, 2020. https://rarediseases. org/rare-diseases/sickle-cell-disease/

3. Chisholm-Burns MA, Schwinghammer TL, Malone PM, Kolesar JM, Lee KC, Bookstaver PB. Pharmacotherapy

Principles \& Practice. 5th ed. McGraw-Hill Education; 2019.

4. Ballas SK, Lusardi M. Hospital readmission for adult acute sickle cell painful episodes: frequency, etiology, and prognostic significance. Am J Hematol. 2005;79(1):17-25.

5. Ballas SK, Gupta K, Adams-Graves P. Sickle cell pain: a critical reappraisal. Blood. 2012;120(18):3647-56.

6. Manwani D, Frenette PS. Vasoocclusion in sickle cell disease: pathophysiology and novel targeted therapies. Blood. 2013;122(24):3892-98.

7. Nietert PJ, Silverstein MD, Abboud MR. Sickle cell anaemia. Pharmacoeconomics. 2002;20(6):357-66.
8. Lanzkron S, Carroll CP, Haywood C. The burden of emergency department use for sickle-cell disease: an analysis of the national emergency department sample database. Am J Hematol. 2010;85(10):797-99.

9. Williams-Gray B, Senreich E.

Challenges and resilience in the lives of adults with sickle cell disease. Soc Work Public Health. 2015;30(1):88-105.

10. Barakat LP, Patterson CA, Daniel LC, Dampier C. Quality of life among adolescents with sickle cell disease: mediation of pain by internalizing symptoms and parenting stress. Health Qual Life Outcomes. 2008;6(60). doi: 10.1186/1477-7525-6-60

11. Epstein K, Yuen E, Riggio JM, Ballas SK, Moleski SM. Utilization of the office, hospital and emergency department for adult sickle cell patients: a five-year study. J Natl Med Assoc. 2006;98(7):1109-13.

12. Wolfson JA, Schrager SM, Khanna R, Coates TD, Kipke MD. Sickle cell disease in California: sociodemographic predictors of emergency department utilization. Pediatr Blood Cancer. 2012;58(1):66-73.

13. Yawn BP, Buchanan GR, Afenyi-Annan AN, et al. Management of sickle cell disease: summary of the 2014 evidencebased report by expert panel members. JAMA. 2014;312(10):1033-48.

14. National Institute for Health and Care Excellence. Sickle cell disease: managing acute painful episodes in hospital. Clinical guideline [CG143]. June 27, 2012. Accessed September 30, 2020. https://www.nice. org.uk/guidance/cg143

15. National Heart, Lung, and Blood Institute. Evidence-based management of sickle cell disease. Expert panel report, 2014. Accessed September 30, 2020. https://www.nhlbi.nih.gov/sites/default/ files/media/docs/sickle-cell-diseasereport\%20020816_0.pdf

16. Rees DC, Olujohungbe AD, Parker NE, Stephens AD, Telfer P, Wright J. Guidelines for the management of the acute painful crisis in sickle cell disease. $\mathrm{Br} \mathrm{J}$ Haematol. 2003;120(5):744-52. 
17. Ballas SK, Bauserman RL, McCarthy WF, et al. Hydroxyurea and acute painful crises in sickle cell anemia: effects on hospital length of stay and opioid utilization during hospitalization, outpatient acute care contacts, and at home. J Pain Symptom Manage. 2010;40(6):870-82.

18. Smith WR, Penberthy LT, Bovbjerg VE, et al. Daily assessment of pain in adults with sickle cell disease. Ann Intern Med. 2008;148(2):94-101.

19. Dampier C, Ely E, Brodecki D, O'Neal P. Home management of pain in sickle cell disease: a daily diary study in children and adolescents. J Pediatr Hematol Oncol. 2002;24(8):643-47.

20. Sinha CB, Bakshi N, Ross D,

Krishnamurti L. Management of chronic pain in adults living with sickle cell disease in the era of the opioid epidemic: a qualitative study. JAMA Netw Open. 2019;2(5):e194410.

21. Stanton MV, Jonassaint CR, Bartholomew FB, et al. The association of optimism and perceived discrimination with health care utilization in adults with sickle cell disease. J Natl Med Assoc. 2010;102(11):1056-64.

22. Elander J, Lusher J, Bevan D, Telfer P. Pain management and symptoms of substance dependence among patients with sickle cell disease. Soc Sci Med. 2003;57(9):1683-96.

23. Williams-Gray B, Senreich E. Challenges and resilience in the lives of adults with sickle cell disease. Soc Work Public Health. 2015;30(1):88-105.

24. Shapiro BS, Benjamin LJ, Payne R, Heidrich G. Sickle cell-related pain: perceptions of medical practitioners. J Pain Symptom Manage. 1997;14(3):168-74.

25. Dowell, D. CDC opioid guideline clarification letter. February 28, 2019. Accessed September 30, 2020. https:// www.nccn.org/professionals/meetings/ oncology_policy_program/pdf/2019_ CDC letter to NCCN ASCO ASH.pdf
26. Charache S, Terrin ML, Moore RD, et al. Effect of hydroxyurea on the frequency of painful crises in sickle cell anemia. N Engl J Med. 1995;332(20):1317-22.

27. Thornburg CD, Calatroni A, Telen M, Kemper AR. Adherence to hydroxyurea therapy in children with sickle cell anemia. J Pediatr. 2010;156(3):415-19.

28. Ritho J, Liu H, Hartzema AG, Lottenberg R. Hydroxyurea use in patients with sickle cell disease in a Medicaid population. Am J Hematol. 2011;86(10):888-90.

29. Candrilli SD, O'Brien SH, Ware RE, Nahata MC, Seiber EE, Balkrishnan R. Hydroxyurea adherence and associated outcomes among Medicaid enrollees with sickle cell disease. Am J Hematol. 2011;86(3):273-77.

30. Anders DG, Tang F, Ledneva T, et al. Hydroxyurea use in young children with sickle cell anemia in New York State. Am J Prev Med. 2016;51(1):S31-S38.

31. Zumberg MS, Reddy S, Boyette RL, Schwartz RJ, Konrad TR, Lottenberg R. Hydroxyurea therapy for sickle cell disease in community-based practices: a survey of Florida and North Carolina hematologists/oncologists. Am J Hematol. 2005;79(2):107-13.

32. Lanzkron S, Haywood C, Hassell KL, Rand C. Provider barriers to hydroxyurea use in adults with sickle cell disease: a survey of the Sickle Cell Disease Adult Provider Network. J Natl Med Assoc. 2008;100(8):968-74.

33. Brandow AM, Jirovec DL, Panepinto JA. Hydroxyurea in children with sickle cell disease: practice patterns and barriers to utilization. Am J Hematol. 2010;85(8):611-13.

34. Zhou J, Han J, Nutescu EA, Gordeuk VR, Saraf SL, Calip GS. Hydroxycarbamide adherence and cumulative dose associated with hospital readmission in sickle cell disease: a 6-year population-based cohort study. Br J Haematol. 2018;182(2):259-70.

35. Lanzkron S, Haywood C Jr, Fagan PJ, Rand CS. Examining the effectiveness of hydroxyurea in people with sickle cell disease. J Health Care Poor Underserved. 2010;21(1):277-86.
36. Han J, Zhou J, Saraf SL, Gordeuk VR, Calip GS. Characterization of opioid use in sickle cell disease. Pharmacoepidemiol Drug Saf. 2018;27(5):479-86.

37. Andrade SE, Kahler KH, Frech F, Chan KA. Methods for evaluation of medication adherence and persistence using automated databases. Pharmacoepidemiol Drug Saf. 2006;15(8):565-74.

38. Hagemann TM, Lewis TV. Chapter 68: Sickle cell anemia. In: Dipiro JT, Talbert RL, Yee GC, Matzke GR, Wells BG, Posey ML. Pharmacotherapy: A Pathophysiologic Approach. 10th ed. McGraw-Hill Education; 2014;1191-206.

39. Dowell D, Haegerich TM, Chou R. CDC guideline for prescribing opioids for chronic pain-United States, 2016. JAMA. 2016;315(15):1624-45.

40. State of Ohio Board of Pharmacy. Oral morphine milligram equivalent conversion table. August 16, 2017. Accessed September 30, 2020. https://www. ohiopmp.gov/Documents/Morphine EquivalentDailyDoseConversionTable.pdf

41. Crosby LE, Barach I, McGrady ME, Kalinyak KA, Eastin AR, Mitchell MJ. Integrating interactive web-based technology to assess adherence and clinical outcomes in pediatric sickle cell disease. Anemia. 2012;2012:1-8.

42. Fisak B, Belkin M, Von Lehe A, Bansal M. The relation between health-related quality of life, treatment adherence and disease severity in a paediatric sickle cell disease sample. Child Care Health Dev. 2012;38(2):204-10.

43. Hilker KA, Jordan SS, Jensen S, Elkin TD, Iyer R. Development of a screening instrument of adherence in pediatric sickle cell disease. Child Health Care. 2006;35(3):235-46.

44. Raphael JL, Butler AM, Rattler TL, Kowalkowski MA, Mueller BU, Giordano TP. Parental information, motivation, and adherence behaviors among children with sickle cell disease. Pediatr Blood Cancer. 2013;60(7):1204-10.

45. Teach SJ, Lillis KA, Grossi M. Compliance with penicillin prophylaxis in patients with sickle cell disease. Arch Pediatr Adolesc Med. 1998;152(3):274-78. 
46. Han J, Saraf SL, Zhang X, et al. Patterns of opioid use in sickle cell disease. Am J Hematol. 2016;91(11):1102-06.

47. Ballas SK, Kanter J, Agodoa I, et al. Opioid utilization patterns in United States individuals with sickle cell disease. Am J Hematol. 2018;93(10):E345-47.

48. Jayawardhana J, Abraham AJ, Perri M. Opioid analgesics in Georgia Medicaid: trends in potential inappropriate prescribing practices by demographic characteristics, 2009-2014. J Manag Care Spec Pharm. 2018;24(9):886-94. doi: 10.18553/ jmcp.2018.24.9.886

49. Campbell G, Nielsen S, Larance B, et al. Pharmaceutical opioid use and dependence among people living with chronic pain: associations observed within the pain and opioids in treatment (POINT) cohort. Pain Med. 2015;16(9):1745-58.

50. Brandow AM, DeBaun MR. Key components of pain management for children and adults with sickle cell disease. Hematol Oncol Clin North Am. 2018;32(3):535-50.

51. Ruta NS, Ballas SK. The opioid drug epidemic and sickle cell disease: guilt by association. Pain Med. 2016;17(10):1793-98.
52. Centers for Medicare \& Medicaid Services. The invisible crisis: understanding pain management in Medicare beneficiaries with sickle cell disease. September 2018. Accessed September 30, 2020. https://www.cms.gov/About-CMS/ Agency-Information/OMH/research-anddata/information-products/data-highlights/Understanding-Pain-Managementin-Medicare-Beneficiaries-with-SickleCell-Disease-

53. Walsh KE, Cutrona SL, Kavanagh PL, et al. Medication adherence among pediatric patients with sickle cell disease: a systematic review. Pediatrics. 2014;134(6):1175-83.

54. Dean AJ, Walters J, Hall A. A systematic review of interventions to enhance medication adherence in children and adolescents with chronic illness. Arch Dis Child. 2010;95(9):717-23.

55. Kahana S, Drotar D, Frazier T. Metaanalysis of psychological interventions to promote adherence to treatment in pediatric chronic health conditions. J Pediatr Psychol. 2008;33(6):590-611.
56. Ehde DM, Dillworth TM, Turner JA. Cognitive-behavioral therapy for individuals with chronic pain: efficacy, innovations, and directions for research. Am Psychol. 2014;69(2):153-66.

57. Murphy J, McKellar J, Raffa S, Clark M, Kerns R, Karlin B. Cognitive behavioral therapy for chronic pain among veterans: therapist manual. US Department of Veterans Affairs. 2014. Accessed September 30, 2020. https://www.va.gov/ PAINMANAGEMENT/docs/CBT-CP_ Therapist_Manual.pdf

58. Woods K, Karrison T, Koshy M, Patel A, Friedmann P, Cassel C. Hospital utilization patterns and costs for adult sickle cell patients in Illinois. Public Health Rep. 1997;112(1):44-51.

59. Amendah DD, Mvundura M, Kavanagh PL, Sprinz PG, Grosse SD. Sickle cell disease-related pediatric medical expenditures in the US. Am J Prev Med. 2010;38(4):S550-S56. 